\title{
PELATIHAN CARA KERJA TENAGA HIDROLIK PADA SISTEM PENGENDALI ALAT BERAT
}

\author{
Agus Dwi Putra ${ }^{1}$, Candra Pradhana ${ }^{2}$, Erlillah Rizqi Kusuma Pradani ${ }^{3}$, Indah Martha \\ Fitriani $^{4}$, Ratna Fajarwati Meditama ${ }^{5}$ \\ ${ }^{1,2,3,4,5)}$ Fakultas Sains dan Teknologi, Universitas Islam Raden Rahmat Malang \\ e-mail:agus_dwi_putra@uniramalang.ac.id
}

\begin{abstract}
Abstrak
Pelatihan berguna dalam meningkatkan mutu dan pengetahuan terutama pada bidang Pendidikan. Pengetahuan juga dapat meningkatkan mutu keterampilan peserta didik terutama yang bergerak dalam bidang kejuruhan. Dalam mewujudkan peserta didik yang kompeten di SMK Muhammadiyah terutama pada jurusan alat berat diperlukan pelatihan terutama pada sistem hidrolik. Sistem hidrolik adalah sistem dalam alat berat yang diapat dikatakan sistem vital karena sebagai sumber tenaga aktuator. Pelatihan berjalan selama 2 hari yakni 7 Februari hingga 8 Februari 2020 dengan kurun waktu 14 jam. Dalam pelatihan sistem hidrolik diikuti oleh siswa dan Sebagian guru produktif alat berat yang mana jumlahnya mencapai 20 peserta. Pada hari pertama dilaksanakan pelatihan dengan tema pengenalan sistem dasar hidrolik dan komponennya. Pada hari kedua dilaksanakan pelatihan dengan tema pemeliharaan dan pemeriksaan sistem hidrolik. Dengan adanya pelatihan ini dimaksudkan dan berguna untuk meningkatkan pengetahuan dan keterampilan pendidik maupun peserta didik dalam bidan alat berat.
\end{abstract}

Kata kunci: Pelatihan, Sistem Hidrolik, Alat Berat

\begin{abstract}
Training is useful in improving quality and knowledge, especially in the field of education. Knowledge can also improve the quality of skills of students, especially those engaged in the field of labor. In realizing competent students at SMK Muhammadiyah, especially in the heavy equipment department, training is needed, especially in the hydraulic sistem. The hydraulic sistem is a sistem in heavy equipment that is considered a vital sistem because it is a source of actuator power. The training runs for 2 days, namely 7 February to 8 February 2020 with a period of 14 hours. The hydraulic sistem training was attended by students and some heavy equipment productive teachers, which number reached 20 participants. On the first day, a training was held with the theme of introducing the basic hydraulic sistem and its components. On the second day, a training was held with the theme of maintenance and inspection of the hydraulic sistem. With this training is intended and useful to increase the knowledge and skills of educators and students in heavy equipment midwives.
\end{abstract}

Keywords: Training, Hydraulic Sistem, Heavy Equipment 


\section{PENDAHULUAN}

Sistem hidrolik alat berat adalah salah satu sistem vital dalam alat berat karena kinerja yang dilakukan dalam satu unit alat berat sengat bergantung pada kinerja sistem hidrolik (Cieslak et al., 2014). Hal ini dapat dilihat dari chasis dan rangka unit alat berat misalnya PC 200 dimana, seluruh rangka dari PC 200 terdapat sirkuit aliran hidrolik.

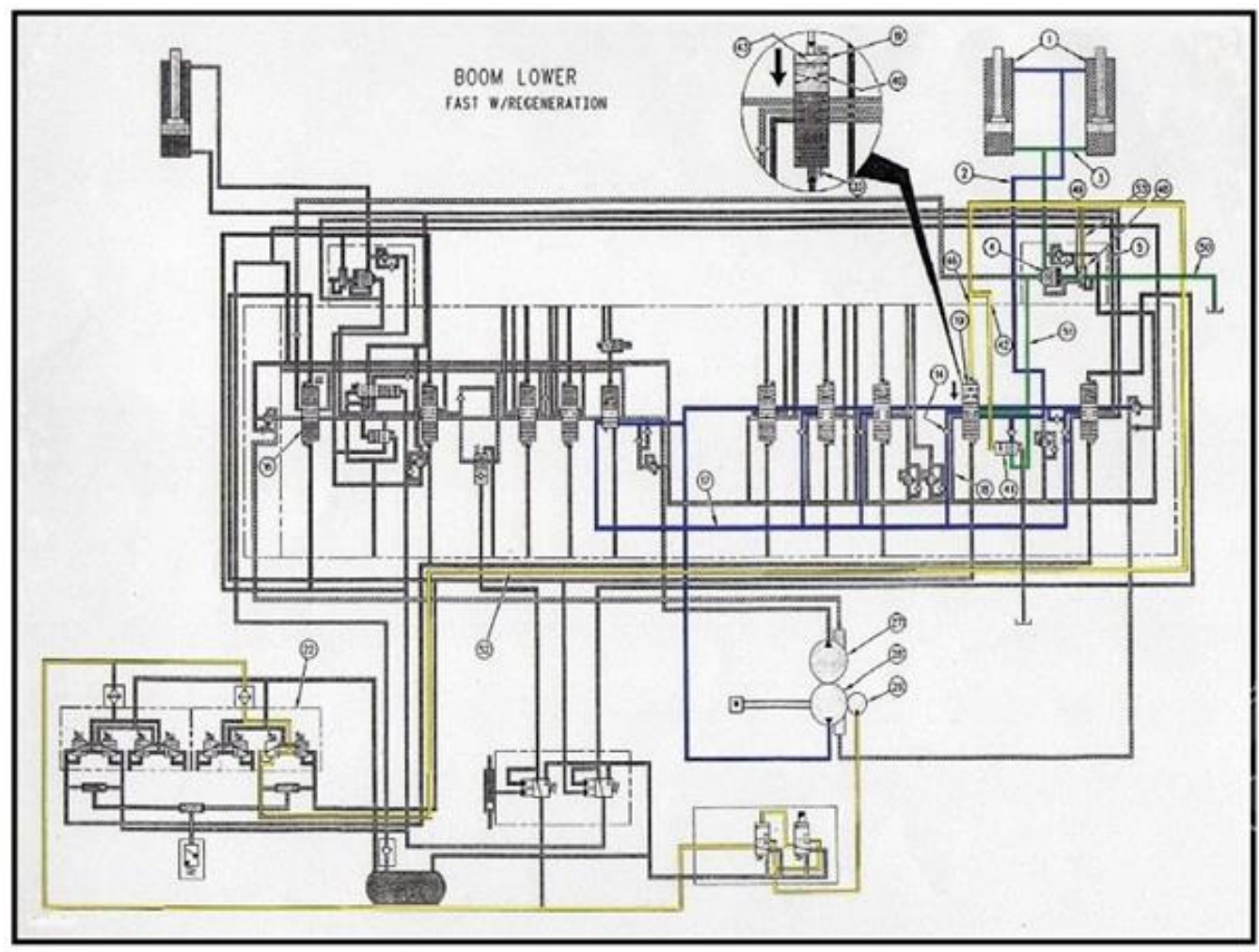

Gambar 1. Sirkuit aliran hidrolik PC 200

Melihat fakta mengenai gambar aliran sirkuit di atas tentunya harus dapat diimbangi dengan persiapa SDM tentang pemahaman dan skillnya dalam merawat sistem hidrolik dalam suatu alat berat. Salah satu usaha pemerintah dalam menyiapkan SDM adalah dengan membentuk prodi Teknik Alat Berat. Prodi ini dibentuk agar mampu menghasilkan tenaga ahli di bidang alat berat terutama mekanik (Hassan \& Taha, 2016).

Tuntunan dunia industri terutama dalam mutu SMK khususnya dalam program studi Teknik alat berat semakin tinggi. Tuntutan yang tinggi ini berjalan senada dengan perkembangan alat berat dalam dunia industri terutama di bidang pertambangan (Adib et al., 2007). Dengan bertambahnya perusahaan pertambangan tentunya diperlukan tenaga kerja yang terampil di bidang teknologi alat berat terutama dalam sistem hidrolik, khususnya bagi SMK pada program studi teknik alat berat untuk meningkatkan kulaitas SDM agar lulusan yang dihasilkan berkompeten (Singh et al., 2018).

SMK Muhammadiyah 1 Kepanjen yang menyelenggarakan Pendidikan menengah kejuruhan di bidang Teknik alat berat telah mengadakan sarana praktik berupa engine stand hidrolik. Meskipun sudah tersedia sarana pembelajaran untuk memenuhi kebutuhan tersebut, para guru yang bertugas mentransfer ilmu kepada para peserta didiknya masih minim pengetahuan tentang teknologi hidrolik. Selain itu, beberapa guru masih belum menguasai secara kompeten terhadap teknologi alat berat terutama dalam sistem hidrolik.

SMK Muhammadiyah 1 Kepanjen adalah salah satu Sekolah Menengah Kejuruhan yang berada di Kepanjen kabupaten Malang, Jwa timur Indonesia. SMK ini sudah berdiri cukup lama mulai tahun 1975 dan mempunyai banyak bidang konsentrasi saat ini. Salah satu bidang konsentrasi baru yang cukup banyak menari peminat adalah konsentrasi alat berat yang mana sudah berjalan 2 tahun. Konsentrasi alat berat ini sangat erat kaitannya dengan sistem hidrolik yang mana siswa-siswanya masih awam dalam memahami konsep dasar hidrolik karena konsentrasi alat 
berat yang baru berjalan 2 tahun. Pelatihan hidrolik ini diharapkan mampu memberikan materi dan wawasan yang nantinya dapat dikembangkan di SMK Muhammadiyah 1 Kepanjen.

Pelatihan hidrolik alat berat ini membahas tentang dasar sistem hidrolik, simbol hidrolik dan prosedur adjusting dan testing pada sistem hidrolik alat berat. Tujuan dari pelatihan ini adalah agar peserta diklat memiliki kompetensi dasar sistem hidrolik alat berat. Materi pelatihan yang akan dipelajari meliputi: dasar sistem hidrolik alat berat, simbol hidrolik dan prosedur adjusting dan Testing pada sistem hidrolik alat berat.

Pelatihan ini disusun berdasarkan rancangan teori dan praktik yang terdiri atas 2 kegiatan belajar yang mencakup tentang dasar sistem hidrolik dan mengidentifikasi jenis - jenis bagian sistem hidrolik alat berat. Pelatihan ini disusun berdasarkan pola teori dan praktik. Untuk mempelajarinya, peserta diklat harus menempuh teori yang diberikan terlebih dahulu sebelum melakukan praktik. Untuk mempermudah pola praktik yang akan dilakukan disediakan gambar, video animasi, cutaway maupun data-data yang lain sehingga peserta diklat akan mudah di dalam belajar.

(Cieslak et al., 2014) mengungkapkan menyatakan bahwa "training is the provision of skills, rules, concepts or behavior in a sistematic manner that results in improved performance in the work environment”. Berdasarkan di atas maka solusi untuk SMK Muhammadiyah 1 Kepanjen dapat ditanggulangi dengan mengadakan pelatihan kepada peserta didik dan pendidik supaya menjadi leboih kompeten dalam bidang alat berat. Selanjutnya (Andoko \& Puspitasari, 2016) berpendapat bahwa adanya pelatihan alat berat dapat meningkatkan tingkat kompetensi dan keterampilan terutama dalam pemeliharaan sistem hidrolik. Berikut akan dideskripsikan beberapa urutan pelatiahan sistem hidrolik yang akan dilaksanakan selama 14 jam.

1. Merumuskan masalah mengenai teknologi hidrolik alat berat dan indentifikasi materi pada kegiatan pelatihan. Langkah dilaksanakan dengan berkunjung ke bengkel alat berat di SMK Muhammadiyah 1 Kepanjen serta melakukan cek kondisi engine stand.

2. Melakukan pelatihan dengan menggunakan Powerpoint materi dan jobsheet. Pemakaian Powerpoint materi diharapkan mampu menambah daya pengetahuan para peserta didik dalam mengikuti pembelajaran teori, sedangkan jobsheet diharapkan mampu membimbing para peserta didik ketika pembelajaran praktik.

3. Pemantauan dan diskusi pemecahan masalah

Pemantauan dan diskusi dilaksanakan pada saat kegiatan pelatihan khususnya pada saat pembelajaran praktik dan trouble shooting.

\section{METODE}

1. Khalayak sasaran

Dalam pelaksanaan kegiatan pelatihan hidrolik ini khalayak yang menjadi target sasaran adalah 20 peserta didik dan pengajar SMK Muhammadiyah 1 Kepanjen.

2. Metode pelatihan

Metode pemberian materi dalam pelatihan ini adalah sebagai beriukut:

a. Ceramah, dalam bagian ini peserta didik diberikan sajian materi berupa powerpoint dan video animasi dari proses cara kerja sistem hidrolik dan teknologinya dalam sistem alat berat teritama pada PC 200. Selama proses peserta pelatihan diberikan berupa modul hidrolik alat berat.

b. Demonstrasi, pada metode demonstrasi disajikan berupa praktik perawatan sistem alat berat mulai dari kontrol maintenance dan penggantian komponen dalam sistem hidrolik. demonstrasi yang dilakuakan mulai dari perawatan secara manual dan perawatan dengan alat computer dan engine scantools.

c. Praktik, yaitu pada bagian job yang telah di demonstrasikan yakni perawatan sistem hidrolik hal selanjutnya adalah memberikan jobsheet pada peserta pelatihan agar melakukan praktik langsung terhadap engine stand yang telah disediakan.

3. Waktu pelaksanaan

Pelaksanaan pelatihan ini dilakuka selama 2 hari yaitu mulai tanggal 7 Februari 2020 sampai 8 Februari 2020. Kegiatan palatihan hidrolik ini dilakukan selama 7 jam perhari sehingga total pelaksanaan yaitu 14 jam. Tempat pelaksanaan yaitu terletak di kampus 2 SMK Muhammadiyah 1 
kepanjen tepatnya di lab TAB. Berikut akan diuraikan jadwal pelaksanaan pelatihan sistem hidrolik.

Tabel 1 Jadwal Pelaksanaan Kegiatan

\begin{tabular}{|c|c|c|c|}
\hline No & Hari & Jam & Kegiatan \\
\hline \multirow[t]{6}{*}{1} & \multirow[t]{6}{*}{ Jum'at, 7 Februari 2020} & $08.00-08.20 \mathrm{WIB}$ & Absensi Hadir \\
\hline & & $08.20-10.00 \mathrm{WIB}$ & $\begin{array}{l}\text { Penguatan dasar sistem } \\
\text { hidrolik }\end{array}$ \\
\hline & & $10.00-10.15 \mathrm{WIB}$ & Istirahat \\
\hline & & $10.15-14.00 \mathrm{WIB}$ & $\begin{array}{l}\text { Sistem dasar Hidrolik di } \\
\text { Unit Alat Berat }\end{array}$ \\
\hline & & $14.00-14.30 \mathrm{WIB}$ & Tanya jawab \\
\hline & & $14.30-15.00 \mathrm{WIB}$ & Absensi Pulang \\
\hline \multirow[t]{6}{*}{2} & \multirow[t]{6}{*}{ Sabtu, 8 Februari 2020} & $08.00-08.20 \mathrm{WIB}$ & Absensi Hadir \\
\hline & & $08.20-10.00 \mathrm{WIB}$ & Penguatan materi \\
\hline & & $10.00-10.15 \mathrm{WIB}$ & Istirahat \\
\hline & & $10.15-14.00 \mathrm{WIB}$ & $\begin{array}{l}\text { Unjuk kerja pada unit } \\
\text { trainer yang telah } \\
\text { disediakan }\end{array}$ \\
\hline & & $14.00-14.30 \mathrm{WIB}$ & Tanya jawab \\
\hline & & $14.30-15.00 \mathrm{WIB}$ & Absensi Pulang \\
\hline
\end{tabular}

\section{HASIL DAN PEMBAHASAN}

1. Pra kegiatan pelaksanaan

Pra kegiatan pelaksanaan merupakan kegiatan yang mana dalam melakukan suatu pengabdian. Pada Langkah ini tim melakukan obeservasi secara langsung dengan mengunjungi SMK Muhammadiyah 1 Kepanjen terutama pada laboratorium TAB (Teknik Alat Berat) dengan melihat engine stand dan wawancara dengan pendidik serta peserta didik yang berada di sana. Dari hasil observasi didapatkan hasil yang mana tim dapat melaksanakan suatu perencanaan kegiatan pelatihan yang akan dilakukan.

Kegiatan pelatihan dabagi menjadi 2 sesi yakni sesi pertama berupa teori dan sesi ke dua berupa praktik. Pada sesi teori tim melakukan identifikasi materi yang digunakan selama proses pelatihan yang meliputi: a) dasar-dasar hidrolik; b) komponen dan cara kerja sistem hidrolik dalam hukum fisika dan kenyataan sehari-hari; c) sistem aliran kerja hidrolik PC 200; d) perawatan berkala sistem hidrolik.

Materi dalam pelatihan dikemas pada bentuk powerpoint, modul dan video, sedangakn pada sesi kedua yakni parktik yaitu dengan membuat suatu jobsheet agar mudah dalam melakukan praktik perawat hidrolik secara langsung. Perangkat pelatihan sistem hidrolik dapat dilihat pada gambar berikut. 


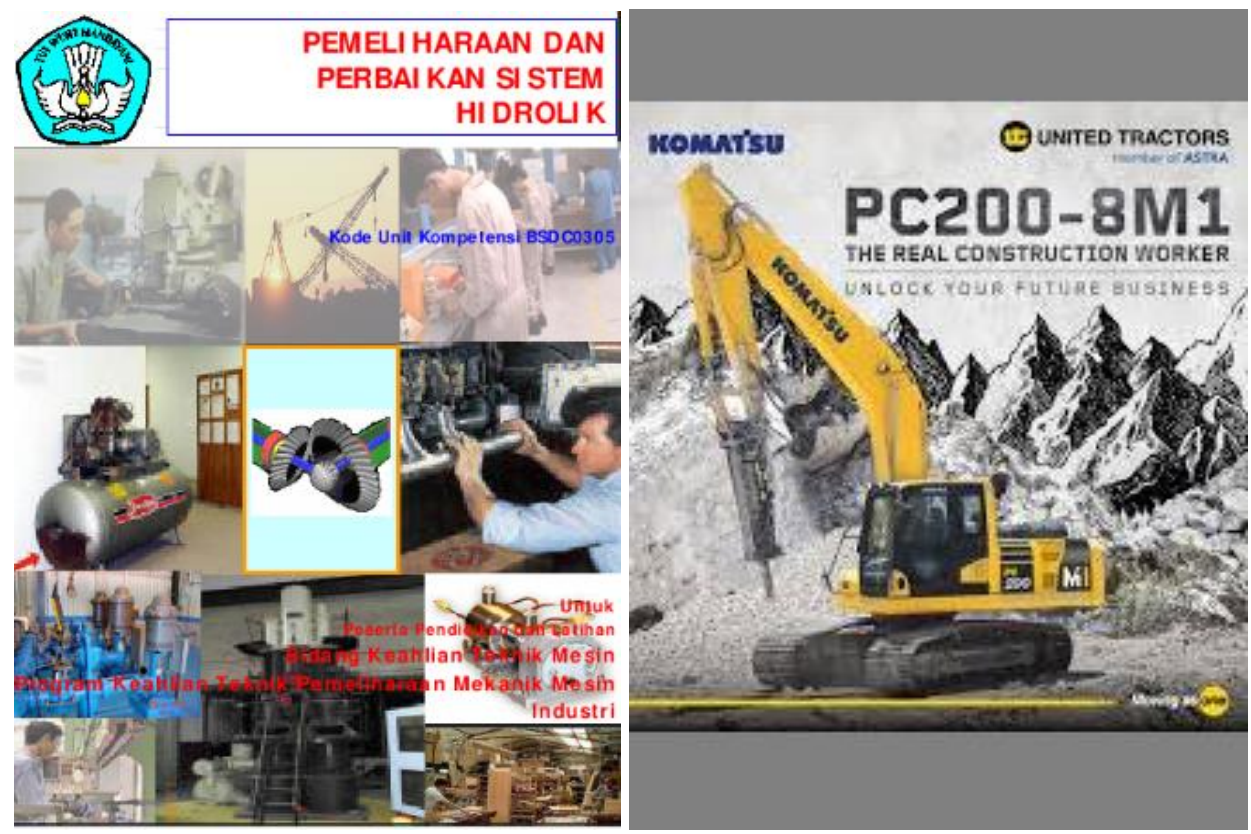

Gambar 2. Modul perbaikan dan perawatan sistem hidrolik

\section{Kegiatan pelaksanaan pengabdian}

Kegiatan pelaksanaan pengabdian yang dilakukan dalam kurun waktu 2 hari dibagi menjadi 2 sesi yaitu teori dan praktik unjuk kerja. Materi yang diberikan pada sesi pertam yaitu teori yakni: a) dasar-dasar hidrolik; b) komponen dan cara kerja sistem hidrolik dalam hukum fisika dan kenyataan sehari-hari; c) sistem aliran kerja hidrolik PC 200. Pada sesi teori instruktur memberikan materi dengan ceramah yang didukung dengan pengisian modul oleh peserta pelatihan. Agar mempermudah penyampaian materi maka, instruktur juga memberikan beberapa cuplikan video dan memberikan demonstrasi dengan benda peraga secara langsung. Dalam penyampaian video dan demosntrasi dengan alat peraga para peserta pelatihan terlihat antusias dalam mengikuti kegiatan.

Pada sesi kedua yaitu sesi praktik peserta pelatihan dibagi menjadi 4 kelompok dengan beranggotakan masing-masing 5 peserta. Materi yang diberikan pada sesi kedua adalah: a) perawatan berkala sistem hidrolik; dan b) pemeriksaan dan diagnosis komponen sistem hidrolik. Pada sesi praktik ini peserta pelatihan memecahkan kasus kerusakan aliran sistem hidrolik dan sebagian besar peserta pelatihan dapat memperbaiki secara langsung troubleshooting yang ada.

Untuk mengukur pemahaman hasil dari pelatihan peserta didik diberikan pre-test dan posttest. Pre-test diberikan pada saat sebelum pelatihan berlangsung sedangkan posttest diberikan setelah kegiatan pelatihan tersampaikan seluruhnya. Hasil perbandingan nilai pre-test dan posttest menunjukkan perbedaan signifikan yang mana hasil posttest meningkat cukup pesat. Berikut adalah table perbandingan hasil pre-test dan posttest.

\begin{tabular}{|c|c|c|c|c|}
\hline Hasil & $\mathbf{N}$ & Min & Maks & Mean \\
\hline Pre-test & 20 & 35 & 78 & 51,20 \\
\hline Posttest & 20 & 40 & 95 & 70,40 \\
\hline
\end{tabular}

Pada tabel 2 dapat dilihat bahwa skor minimal pada pre-test adalah 35, sedangkan pada posttest didapatkan skor minimal sebesar 40. Skor maksimum pada hasil pre-test didapatkan skor sebesar 78, sedangkan skor maksimum pada posttest sebesar 95. Rata-rata pada hasil pre-test adalah sebesar 51,20 serta nilai rata-rata pada posttest sebesar 70,40. Dari tabel 3 di atas dapat ditarik kesimpulan bahwa dengan adanya pelatihan sistem hidrolik dapat meningkatkan kompetensi guru dan peserta didik.

a. Faktor Pendukung 
Faktor pendukung dalam terlaksananya kegiatan pelatihan ini adalah adanya dukungan dana dari pihak LP3M UST dan SMK Muhammdiyah 1 Kepanjen. Tersedianya dukungan media pembelajaran seperti engine stand hidrolik, panel board hdirolik dan scanncer hidrolik juga menjadi salah satu faktor pendukung. Hal lain yang juga sangat mendukung adalah antusias peserta dalam mengikuti kegiatan pelatihan ini karena bagi peserta didik pelatihan semacam ini adalah hal yang baru dan menarik untuk dipelajari serta mudah diterapkan.

b. Faktor Penghambat

Faktor penghambat yang ditemukan dalam kegiatan pelatihan ini adalah terbatasnya jumlah varian mesin hidrolik yang ada.

\section{SIMPULAN}

Kegiatan pelatihan semacam ini dapat meningkatkan kemampuan para peserta didik dalam mengikuti perkembangan teknologi. Dengan meningkatnya kemampuan para peserta didik terhadap teknologi sistem hidrolik diharapkan para peserta didik mampu menyesuaikan kebutuhan kompetensi yang dibutuhkan oleh dunia industri dan usaha khususnya alat berat dan pertambangan Dengan demikian, pada saat para peserta didik lulus sekolah dapat mengisi kebutuhan tenaga kerja.

\section{SARAN}

Jumlah dan varian mesin hidrolik sebaiknya ditambah, sehingga pada nantinya dapat dipisahkan mesin hidrolik yang untuk bongkar - pasang dan untuk diagnosis. Dengan pemisahan seperti ini para peserta didik dapat melakukan praktik secara luas, sehingga skill dan pengetahuannya meningkat.

\section{UCAPAN TERIMA KASIH}

Penulis mengucapkan terima kasih kepada:

1. Drs. Maryanto, MM., selaku kepala SMK Muhammadiyah yang telah memberikan izin untuk melakukan kegiatan pelatihan sistem hidrolik.

2. Mojibur Rohman, M.Pd, selaku Dekan Fakultas Sains dan Teknologi, Universitas Islam Raden Rahmat Malang yang telah mengirimkan tugas agar memberikan pelatihan dan pengabdian masyarakat.

3. Drs. Hono Suparjo, selaku ketua coordinator program studi jurusan Teknik alat berat SMK Muhammadiyah 1 Kepanjen.

4. Sunaryo, S.T, selaku ketua jurusan Teknik otomotif SMK Muhammadiyah 1 Kepanjen.

\section{DAFTAR PUSTAKA}

Adib, A. M. L., Baptista, C. A. R. P., Barboza, M. J. R., Haga, C., \& Marques, C. C. F. (2007). Aircraft engine bleed system tubes: Material and failure mode analysis. Engineering Failure Analysis, 14(8 SPEC. ISS.), 1605-1617. https://doi.org/10.1016/j.engfailanal.2006.11.053

Andoko, \& Puspitasari, P. (2016). Finite element analysis of surface tension on piston due to pressure variation. AIP Conference Proceedings, 1778. https://doi.org/10.1063/1.4965798

Cieslak, J., Efimov, D., Zolghadri, A., Gheorghe, A., Goupil, P., \& Dayre, R. (2014). A method for actuator lock-in-place failure detection in aircraft control surface servo-loops. In IFAC Proceedings Volumes (IFAC-PapersOnline) (Vol. 19, Issue 3). IFAC. https://doi.org/10.3182/20140824-6-ZA-1003.02158

Hassan, A. M., \& Taha, H. E. (2016). Airplane loss of control problem: Linear controllability analysis. Aerospace Science and Technology, 55, 264-271. https://doi.org/10.1016/j.ast.2016.06.001

Singh, R. R., Kumar, B. A., Shruthi, D., Panda, R., \& Raj, C. T. (2018). Review and experimental illustrations of electronic load controller used in standalone Micro-Hydro generating plants. Engineering Science and Technology, an International Journal, 21(5), 886-900. https://doi.org/10.1016/j.jestch.2018.07.006 